\title{
Effect of Plasmonic Nanoparticles on the Electric Field Strength to Improve Performance of Single Crystalline Solar Cell
}

\author{
Samah Mohammed Al-Karawi ${ }^{1}$, Mohammed Fawzi Mohammed Altemimi ${ }^{*}$
}

\section{Authors affiliations:}

1) M.Sc. student, Laser and Optoelectronics Engineering Dep., Al-Nahrain University, BaghdadIraq.

samahmohammed9321@yahoo.com

$2^{*}$ Laser and Optoelectronics Engineering Dep., Al-Nahrain University, Baghdad, Iraq. mohamedaft82@gmail.com

\section{Paper History:}

Received: $6^{\text {th }}$ July 2019

Revised: 26 ${ }^{\text {th }}$ Sep. 2019

Accepted: $11^{\text {th }}$ Dec. 2019

\begin{abstract}
The effect of metal nanoparticles (MNPs) on the electric field strength and distribution for improvement solar cell performance is investigated and simulated. By manipulating the properties of nanoparticles, distribution of the electric field was altered. In this paper, classical solar cell ( $\mathrm{p}-\mathrm{n}$ junction) and improved structure (add an extra layer of $\mathrm{SiO} 2$ and gold nanoparticles on the top of $\mathrm{p}-\mathrm{n}$ junction) is simulated. Different sizes of NPs, thickness of $\mathrm{SiO} 2$ sublayer, and spacing distance between NPs is done to improving the electric field and showing plamonic effect. Gold NPs deposition on single crystalline silicon solar cell is modelled by COMSOL $5.22 \mathrm{D}$, Electromagnetic wave propagation in the frequency domain with periodic boundary conditions. The best wavelength found in our work is $550 \mathrm{~nm}$. The electric field enhances when the size of NPs increases but it must be limited. When gold NPs are deposited on the SiO2 sublayer, the plasmonic effect appears due to decreasing the refractive index. Moreover, separation distance between NPs affect the electric field enhancement by manipulating the number of NPs, the distance decreases and the plasmonic interaction appears.
\end{abstract}

Keywords: Plasmonic, Nanoparticle, Electric Field, Solar Cell.

$$
\begin{aligned}
& \text { تأثير الجسيات النانوية على قوة المجال الكهربائي لتحسين أداء الخلية الشمسية } \\
& \text { البلورية المفردة } \\
& \text { سماح محمد الكرعاوي ، محمد فوزي محمد التيمي }
\end{aligned}
$$

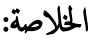

$$
\begin{aligned}
& \text { تم دراسة تأثير الجسيهات النانوية المعدنية على قوة المجال الكهربائي وتوزيعه لتحسين أداء الخلايا الشمسية }
\end{aligned}
$$

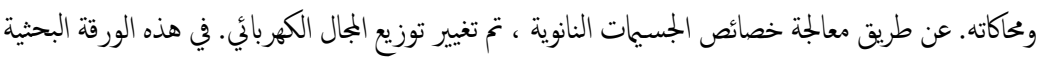

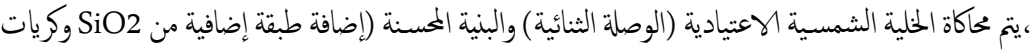

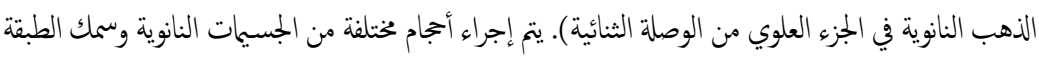

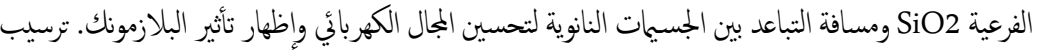

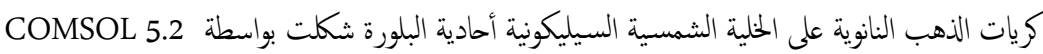

$$
\begin{aligned}
& \text { 2D }
\end{aligned}
$$

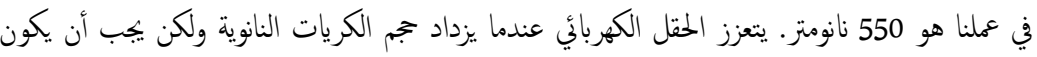

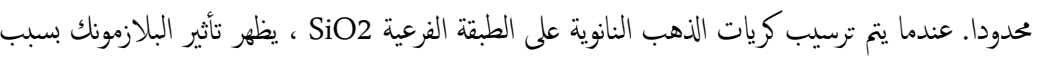

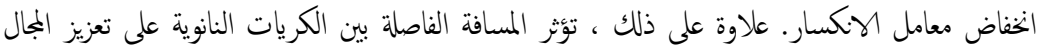

$$
\begin{aligned}
& \text { الكهربائي عن طريق التلاعب بعددهم، تقل المسافة ويظهر التفاعل البلازي. تلإي. }
\end{aligned}
$$

NJES is an open access Journal with ISSN 2521-9154 and eISSN 2521-9162

This work is licensed under a Creative Commons Attribution-NonCommercial 4.0 International License 


\section{Introduction}

A solar cell is a device that coverts sunlight directly into electricity based on the photovoltaic effect [1]. Silicon is the material of choice for photovoltaic applications due to its low cost, abundance in nature, nontoxicity, long-term stability, and well-established technology [2]. The main requirements for ideal solar cell material are (a) direct band structure, (b) band gap more than $1.1 \mathrm{eV}$, (c) consisting of readily available and non-toxic materials, (d) good photovoltaic conversion efficiency, (e) long-term stability [3]. The c-Si solar cell is the substrate which will be used for the nanotechnology applications due to its many advantages. First of all, the c-Si solar cell exhibits better predictable and uniform behavior than other siliconbased solar cells during experimentation, which allows it to match most of the theoretical and technique developments required in the photovoltaic field. Secondly, it has the highest efficiency rate in all siliconbased solar cells given the standard condition that they are made out of the highest purity silicon. Thirdly, the c-Si solar cell has the longest lifetime than other silicon-based solar cells due to its high purity level [4]. The single-crystalline silicon solar cells are most popular compared to polycrystalline and amorphous silicon solar cell due to better efficiency [5].

High-efficiency silicon solar cells strongly rely on an effective reduction of charge carrier recombination at their surfaces, i.e. surface passivation. Today's industrial silicon solar cells often utilize dielectric surface passivation layers such as $\mathrm{SiN}_{\mathrm{x}}$ and $\mathrm{Al}_{2} \mathrm{O}_{3}$. However, a passivation layer well-known from the microelectronic industry, $\mathrm{SiO}_{2}$, had and has a strong impact on silicon photovoltaics [6]. The refractive index of the surrounding medium was important for the light scattering ability of MNPs. By using a low refractive index medium as a sublayer between the MNPs and the solar cell, the light scattering ability of MNPs was increased. More light scattered into solar cell caused increased electric field intensity under the MNPs [4].

Noble metals such as silver (Ag), gold (Au), aluminum $(\mathrm{Al})$ and copper $(\mathrm{Cu})$, support surface plasmon due to their free electron like behavior. Surface plasmon is the collective oscillations of excited free electrons of metallic particles. This unique property of (MNPs) can be used to enhance the optical absorption of solar cells through scattering of light and near-field concentration of light $[7,8]$.

Hence, we are improving a new study for comparing between a classical solar cell and our improving structure in different important parameter in solar cells. Sections (2) describes brief about plasmonic MNPs. Section (3) presents the equation of electromagnetic wave that used by COMSOL program for the simulation and presents the three structures of solar cell. Section (4) introduces the result and discussion for the three structures and effect of (size, thickness of $\mathrm{SiO} 2$, and spacing distance between NPs) on the electric field enhancement with concluding remarks in Section (5).

\section{Plasmonic Metal Nanoparticles}

Plasmonics is the science studying the optical phenomenon existing at the interface of metal and dielectric material at the nano-scale $[9,10]$. It has attracted significant interest due to its capabilities in localizing and guiding light at the nano-scale [11]. In the recent years, plasmonics has attracted significant attention from the photovoltaic (PV) community due to its advanced light trapping mechanisms for enhancing the light absorption in solar cells $[12,13]$. MNPs are one of many solar cell applications of nanotechnology; they play a significant role in enhancing solar cell optical properties. One of the advantages of applying nanoparticles to solar cells mentioned herein is the ability to scatter incident light to different angles when light illuminates a metal surface. As incident light scatters through the nanoparticles at different angles, light path length through the solar cell substrate is increased. Another advantage of integrating nanoparticles into solar cells is the ability to enhance the localized electric field around the nanoparticles. If the nanoparticles deposit on the solar cell, the electric field inside the cell will be affected by the enhanced localized electric field from the nanoparticles, which results in an increase in photon absorption in the cell [4]. Surface plasmons resonance (SPR) is the collective oscillation of electrons in metal stimulated by illumined light. The SPR condition is established when the frequency of illumined light photons matches the resonance frequency of metal. Therefore, SPR is found in materials that have negative real and small, positive, imaginary dielectric constants, such as noble metals (for examples, silver (Ag) and gold $(\mathrm{Au})$ ), SPR is sensitive to incident light and the surrounding dielectric environment and can be used on different optical devices, like solar cells [14].

Localized surface plasmons resonance (LSPR) is a variation of SPR. LSPR is surface plasmons resonance confined to a metal nanostructure much smaller than the wavelength of illuminated light [15]. The plasmons resonance localizes around the nanostructure with a special frequency called the LSPR frequency. LSPR is sensitive to the surrounding dielectric environment and metal nanoparticle geometry. Due to the successful development of nanoparticle fabrication techniques in recent years, nanoparticles enhancing solar cell electrical properties via LSPR has become a popular topic in solar cell applications. When light is illuminated on metal nanoparticles, the conduction electrons are excited by incident photons. Then, movement of charges in the nanoparticle leads to a build-up of charge on the particle surface. The buildup charge on the surface acts as a restoring force, creating a resonance condition for electrons. Hence, the resonance conduction on metal nanoparticle is 
LSPR [15]. Electromagnetic distribution in different parts of the cell changes by changing the NPs' materials, shape, geometry and inter-distance between them. The plasmonic NPs are used to manipulate the light interaction with matter in the solar cells regions. Because of plasmonic effect, a high electric field builds around metal nanoparticles so that high conversion efficiency is available [16].

In this paper, plasmonic MNPs deposition on $\mathrm{p}-\mathrm{n}$ junction solar cell with manipulation of size, thickness of spacer layer, and spacing distance investigated to improve solar cells performance.

\section{Formulation and Simulations}

Nanoparticles deposition on single crystalline silicon solar cell is modelled as electromagnetic wave propagation in the frequency domain with periodic boundary conditions using COMSOL wave optic module. The equation of electromagnetic wave, frequency domain is [17]:

$$
\nabla \times \mu_{r}^{-1}(\nabla \times E)-k_{0}^{2}\left(\varepsilon_{r}-\frac{j \sigma}{\omega \varepsilon_{0}}\right) E=0 \ldots \text { (1) }
$$

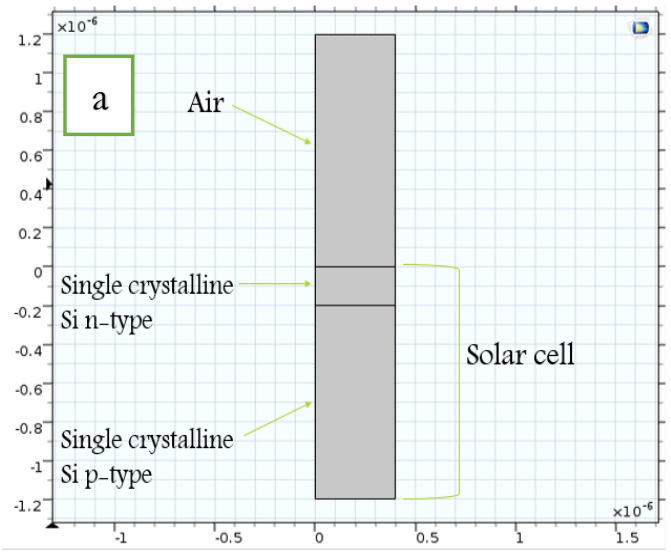

Where $\mu_{r}$ : relative permeability, $k_{0}$ : magnitude of the free-space wave, $\varepsilon_{r}$ : relative permitivity, $\sigma$ : electrical conductivity, $\omega$ : frequency of the incident e$\mathrm{m}$ wave of photons, $\varepsilon_{0}$ : permittivity of free space.

A 2-D model with periodic boundary conditions is considered. The model is set to sweep across the incident wave frequency range in the visible spectrum from $400 \mathrm{~nm}$ to $800 \mathrm{~nm}$. Three structures of solar cell is considered as shown in Fig.1. The first structure is the Classical structure which includes of $\mathrm{p}-\mathrm{n}$ junction (silicon single crystalline) without coating or deposition as shown in Fig.1a. The thicknesses of $\mathrm{p}$ and $\mathrm{n}$ layers are $1 \mu \mathrm{m}$ and $0.2 \mu \mathrm{m}$, respectively, and the width for each other is $0.4 \mu \mathrm{m}$. The second structure is illustrated in Fig.1b, which show the deposition of gold nanoparticles with radius $40 \mathrm{~nm}$ on the top of solar cell (n-type, $n=3.45$ ). The third structure is displayed in Figure 1c, which show coating the n-type by a sublayer $\left(\mathrm{SiO}_{2}, \mathrm{n}=1.458\right)$ with thickness $10 \mathrm{~nm}$. The task of this study is to alter the distribution of the electric field by manipulating the radius of NP, thickness of coating layer and number of NPs.
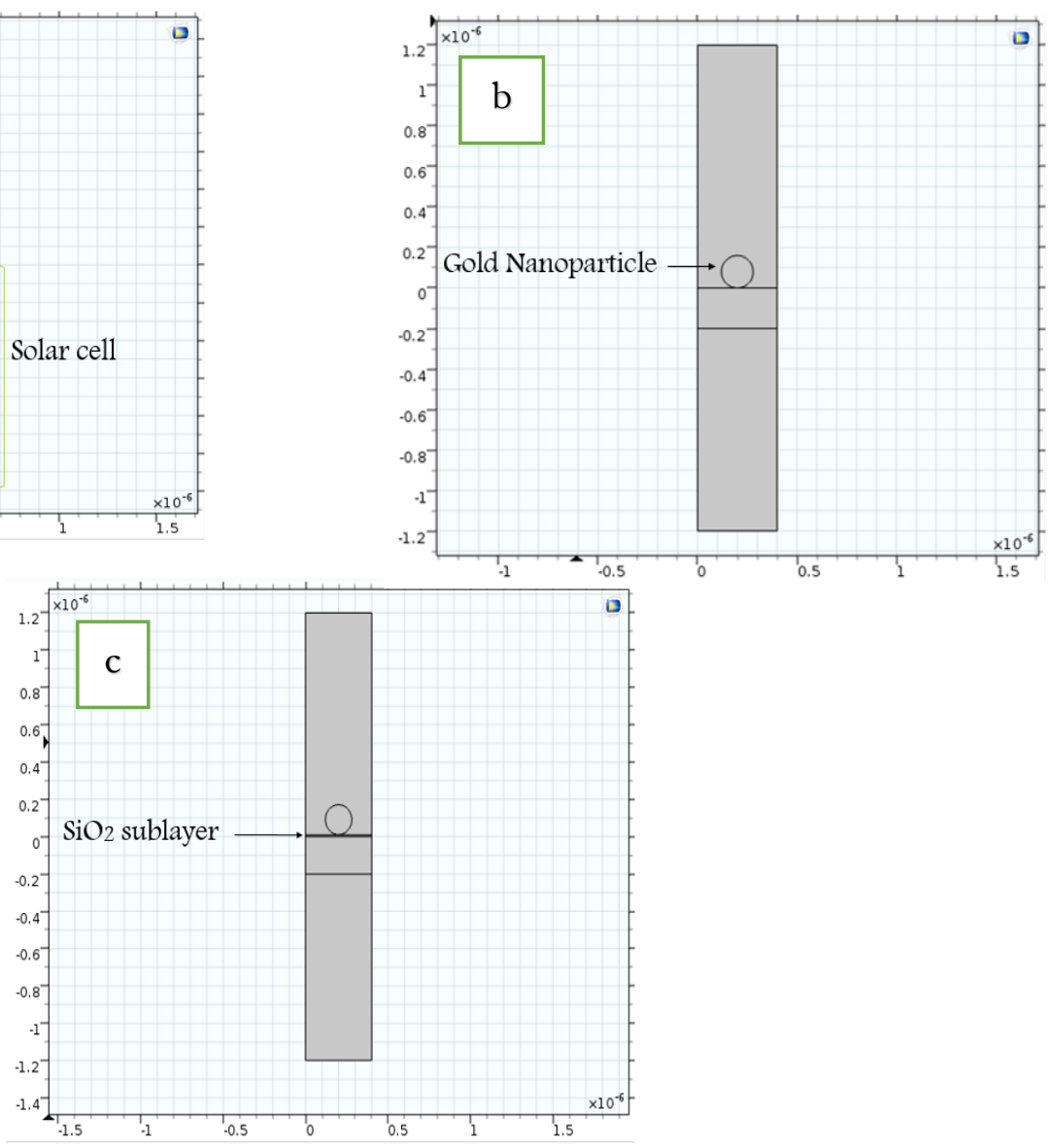

Figure (1): Solar cell structures (a) Classical structure (without NPs), (b) Improved structure (with NPs on n-type), and (c) With NPs on $\mathrm{SiO}_{2}$ sublayer.

\section{Simulation Results and Discussion}

In this section, the result and discussion for the three structures and effect of (size, thickness of $\mathrm{SiO} 2$, and spacing distance between NPs) on the electric field enhancement are demonstrated. Based on the obtained result, we decided the best result which have a high electric field around the NPs.

Fig. 2 show the electric field intensity at $550 \mathrm{~nm}$ in these three different structures. Light is

diffused in different parts of the classical solar cell as shown in Fig.2a. 
In classical structure, light spreads through the air and then moves in a thick area of silicon. When NP deposits on n-type directly, off resonance was

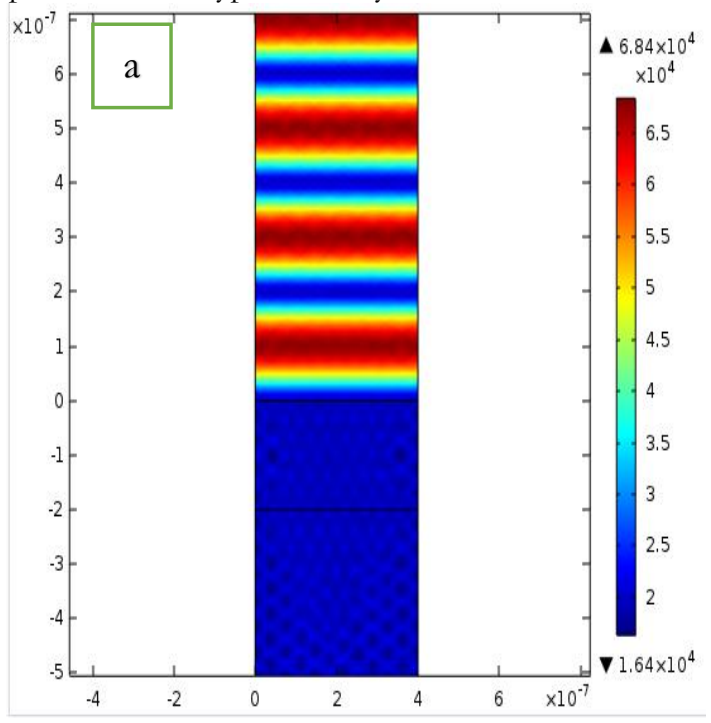

occurred as shown in Fig. 2b, while Fig.2c shows that the plasmonic affects light and make it spread inside the cell when NP deposits on dielectric layer.

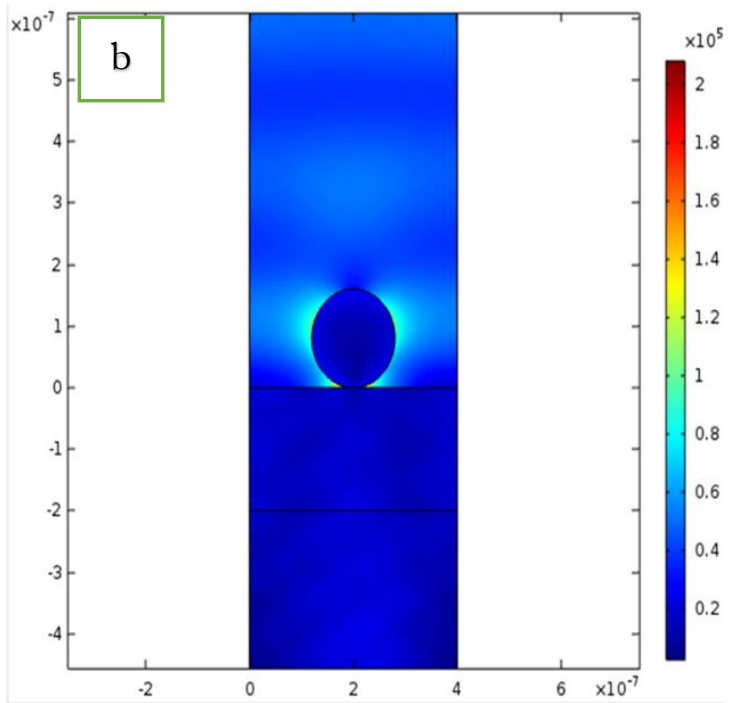

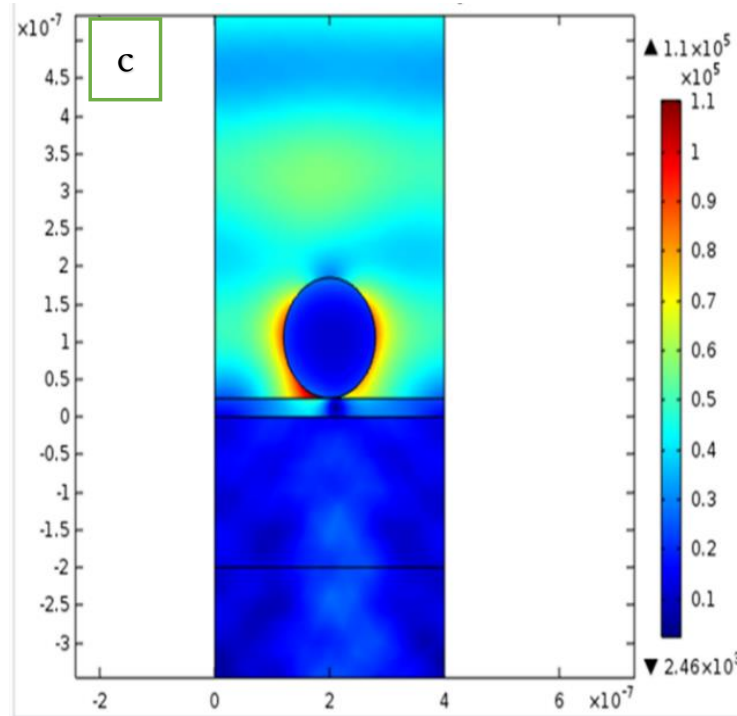

Figure (2): Electric field Intensity at $550 \mathrm{~nm}$ in the (a) Classical structure, (b) improved structure with NPs on n-type, and (c) with NPs on $\mathrm{SiO}_{2}$ sublayer.

\subsection{Influence of NPs Size Variation}

The first important parameter for manipulating the electric field is the size of NPs. Different nanoshere's radius ( $\mathrm{r}$ ) are used from $10 \mathrm{~nm}$ to $80 \mathrm{~nm}$ and the results are illustrated in Fig.3. From Fig.3, we are observed a small sizes give little effect and decrease in the electric field enhancement as shown in Fig.3a. But when the size is increasing, the field intensity increasing as shown in Fig. 3 b and Fig. 3c, then the field decreased at radius $80 \mathrm{~nm}$ as displayed in Fig.3d.
Finally, the electric field alters according to size of NP sketched in Fig.4. From Figure 4, the field decreased when the radius of NP is decreased at $10 \mathrm{~nm}\left(\mathrm{E}=7 * 10^{4}\right.$ $\mathrm{V} / \mathrm{m})$ and then dramatically increase to $(\mathrm{E}=10.8 * 104$ $\mathrm{V} / \mathrm{m}$ and $10.9 * 104 \mathrm{~V} / \mathrm{m})$ at $(40$ and 50$) \mathrm{nm}$, respectively. Then slightly drop to $(\mathrm{E}=10.4 * 104 \mathrm{~V} / \mathrm{m}$ and $10.3 * 104 \mathrm{~V} / \mathrm{m})$ at $(60$ and 80$) \mathrm{nm}$, respectively. We obtained the greatest result when $\mathrm{r}=40 \mathrm{~nm}$ and $\mathrm{r}=$ $50 \mathrm{~nm}$, at $550 \mathrm{~nm}$. 

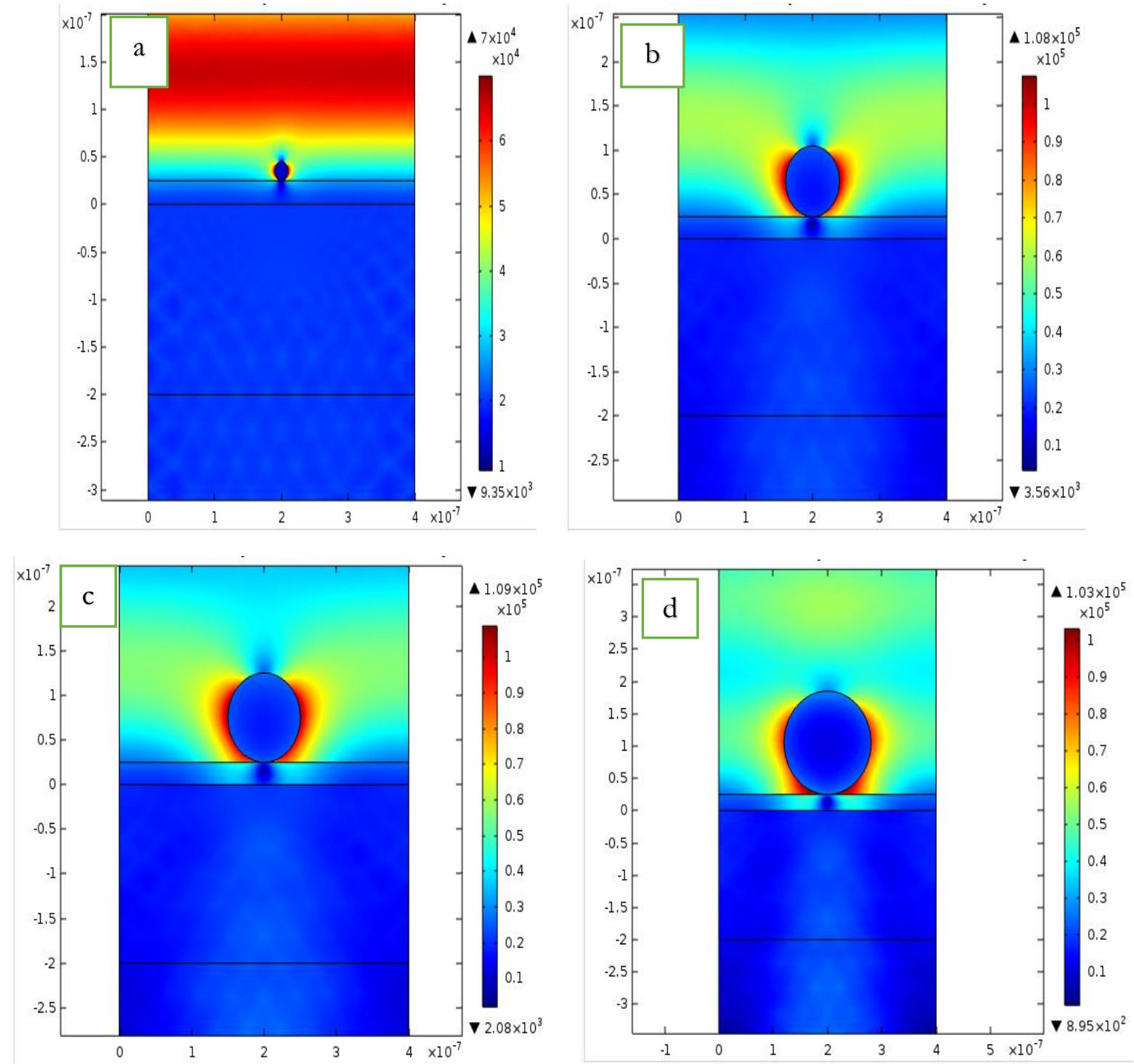

Figure (3): Effect of size of NP on the electric field enhancement, NP radius (a) $10 \mathrm{~nm}$, (b) $40 \mathrm{~nm}$, (c) $50 \mathrm{~nm}$, (d) 80 $\mathrm{nm}$, at $550 \mathrm{~nm}$.

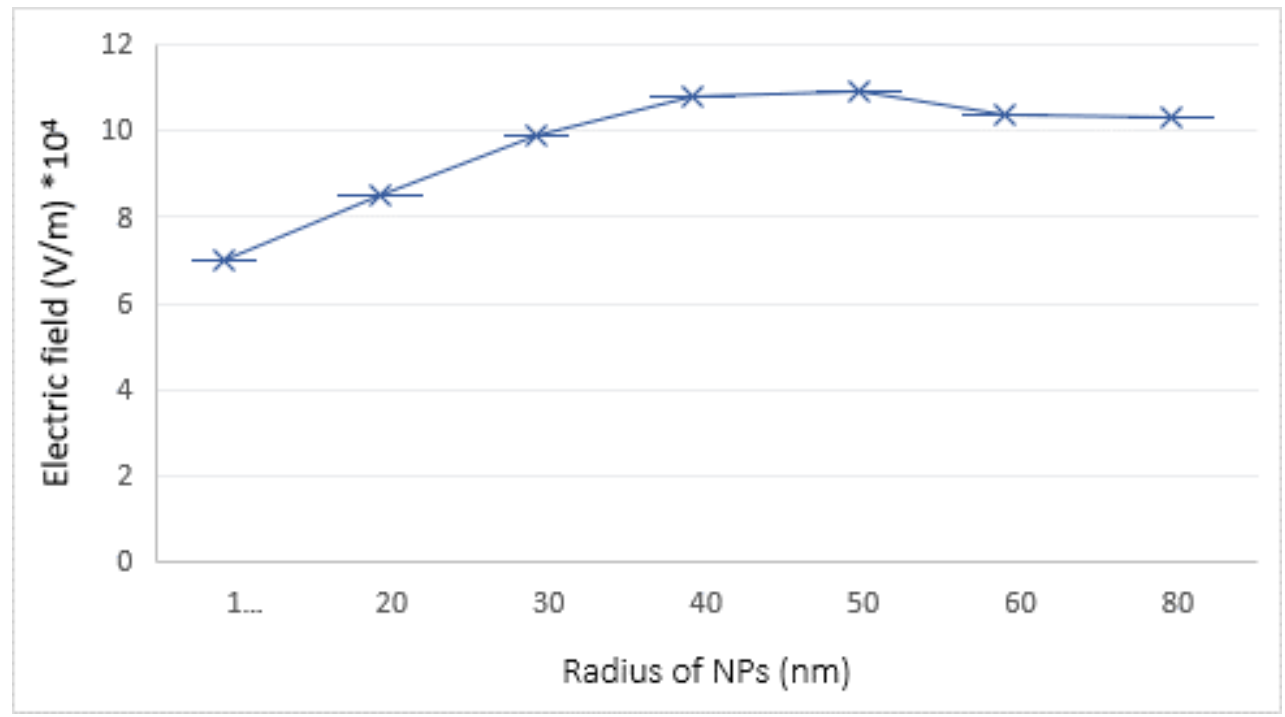

Figure (4): Influence of NP size variation on electric field at $550 \mathrm{~nm}$. 


\subsection{Influence of spacer layer thickness}

The second important parameter is the thickness of spacer layer that effect on the field enhancement. We are used several of thickness from $10 \mathrm{~nm}$ to $50 \mathrm{~nm}$ and we are selected nanosphere with radius $40 \mathrm{~nm}$. Results are show in Fig.5. From Fig.5a, the electric field intensity at thickness $10 \mathrm{~nm}$ is decreased

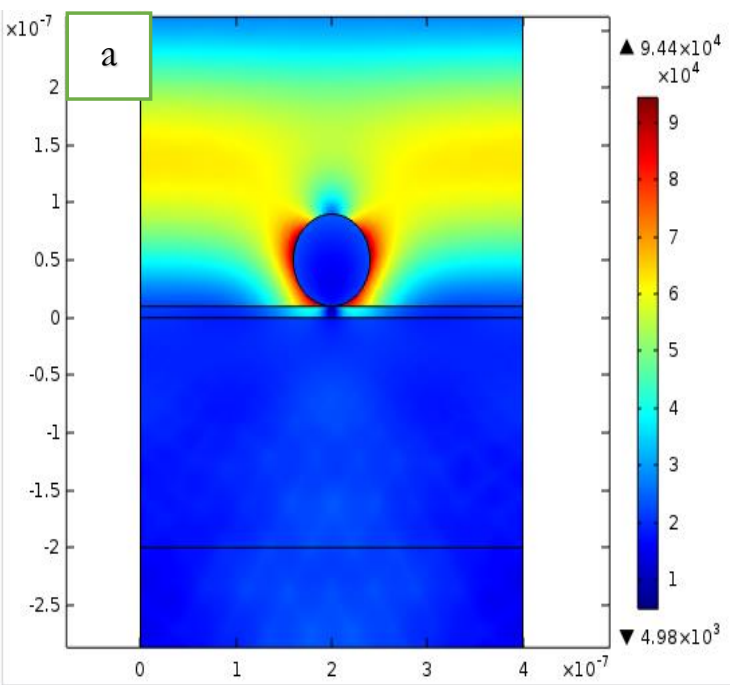

compared with the electric field intensity at $50 \mathrm{~nm}$ and the greatest effect shown in Fig.5b.

Also an important sketch between the electric field altering and the thickness of $\mathrm{SiO}_{2}$ is presented in Fig.6. When the thickness increased the field is increased. At $10 \mathrm{~nm}\left(\mathrm{E}=9.44 * 10^{4} \mathrm{~V} / \mathrm{m}\right)$ and steady raise with increasing the thickness of $\mathrm{SiO}_{2}$ to reach $\left(\mathrm{E}=12^{*} 10^{4}\right.$ $\mathrm{V} / \mathrm{m})$ at $50 \mathrm{~nm}$.

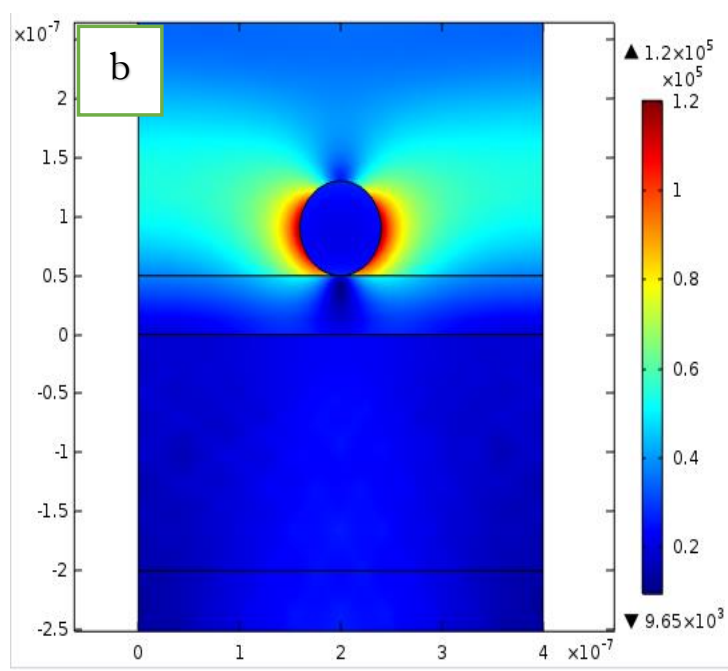

Figure (5): Effect of spacer layer thickness $\left(\mathrm{SiO}_{2}\right.$ sublayer) on the electric field enhancement (a) $10 \mathrm{~nm}$, and (b) 50 $\mathrm{nm}$, at $550 \mathrm{~nm}$.

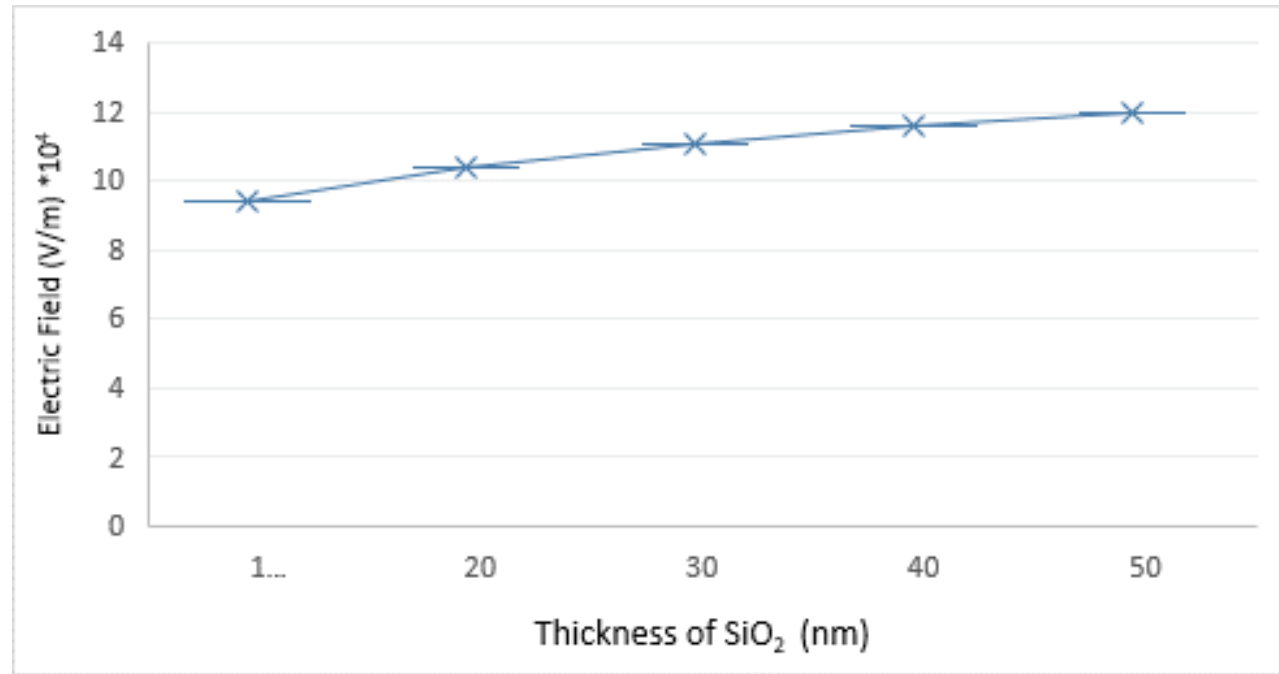

Figure (6): Influence the thickness of $\mathrm{SiO}_{2}$ sublayer on electric field enhancement.

\subsection{Influence of spacing distance}

The third affective parameter on the electric field and plasmonic resonance is the spacing distance (d) between NPs.

By using the COMSOL 5.2 model, the effect of spacing between nanospheres of radius $40 \mathrm{~nm}$ and thickness of $\mathrm{SiO}_{2} 50 \mathrm{~nm}$ on the field enhancement is introduced in Fig.7. It should be noted that with decreased number of nanospheres, the spacing is increased. We manipulate with number of particles and not with size of NPs as presented in reference [7].

We see the plasmonic effect between the two neighboring NPs, when the spacing between nanoparticles is decreased, that shown in Figu.7a and $7 \mathrm{~b}(\mathrm{~d}=0.2$ and $\mathrm{d}=0.25) \mu \mathrm{m}$, respectively. But in Fig. $7 \mathrm{c}$ where $\mathrm{d}=0.3 \mu \mathrm{m}$ the effect starts reducing because increasing the spacing between NPs, the NPs appearance as each separately and no coupling between them, as shown in Fig. $7 d$ where $d=0.4$ $\mu \mathrm{m}$. 

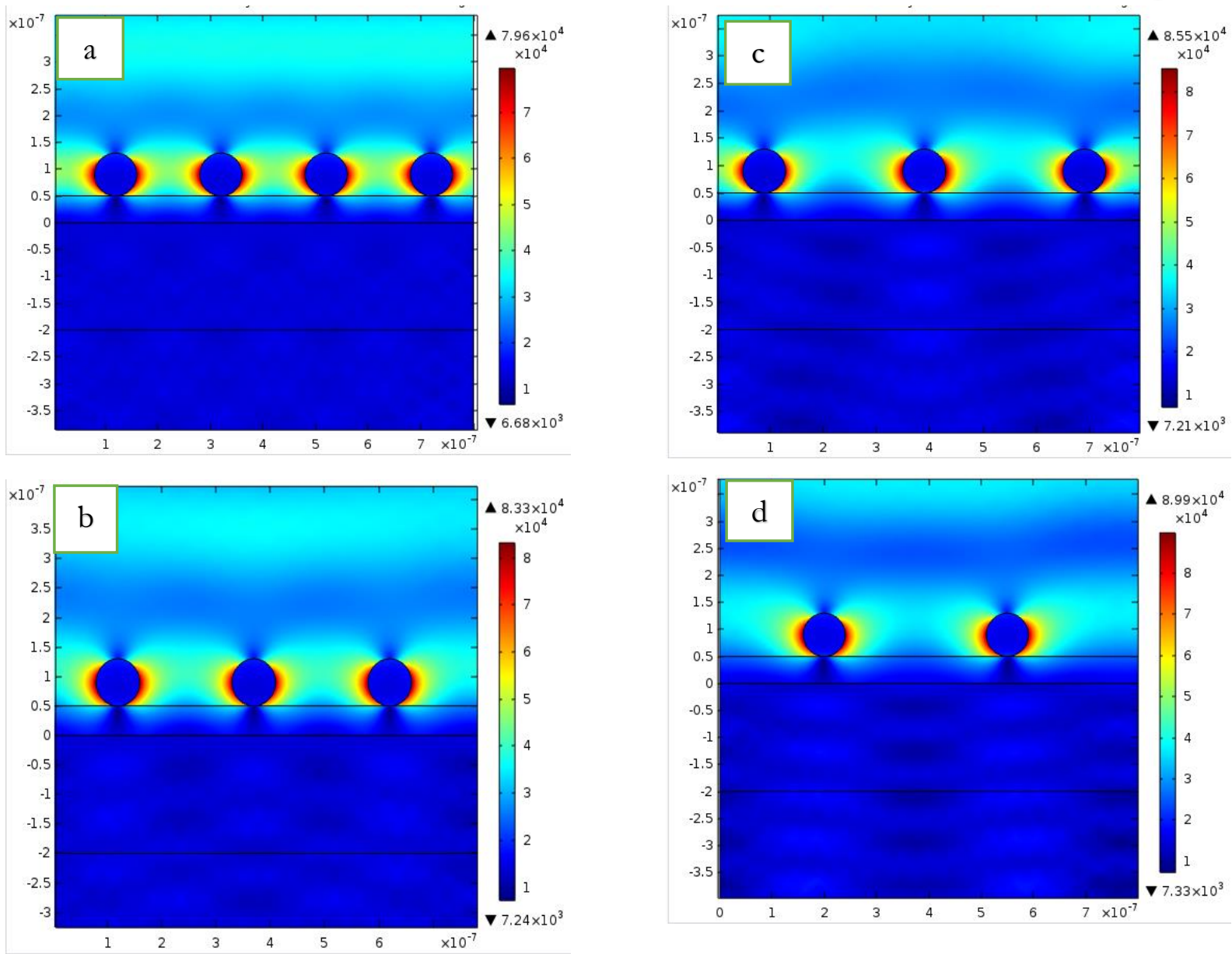

Figure (7): Influence of spacing distance (d) between NPs on the electric field enhancement (a) $d=0.2 \mu \mathrm{m}$, (b) $\mathrm{d}=0.25 \mu \mathrm{m},(\mathrm{c}) \mathrm{d}=0.3 \mu \mathrm{m}$, and (d) $\mathrm{d}=0.4 \mu \mathrm{m}$.

\section{Conclusion}

According to simulation results it was shown that to improve the electric field, the NPs' size, spacing, presence $\mathrm{SiO}_{2}$ sublayer, and thickness of it must be manipulated. The electric field enhances when the size of NPs increases but it must be limited $(80 \mathrm{~nm}$ and 100 $\mathrm{nm})$ diameter. When gold NPs are deposited on the $\mathrm{SiO}_{2}$ sublayer, the electric field increased due to decreasing the refractive index $\left(\mathrm{n}_{\text {sio } 2}=1.458\right)$. The electric field increases when the sublayer thickness increases to $50 \mathrm{~nm}$, and we obtain on the greatest effect. Moreover, separation between NPs affect the electric field enhancement by manipulating the number of NPs the distance decreases and the plasmonic interaction appears.

\section{References}

[1] Green, Martin A. "Photovoltaics: technology overview." Energy policy 28.14 (2000): 989-998.

[2] Pillai, S., et al. "Surface plasmon enhanced silicon solar cells." Journal of applied physics 101.9 (2007): 093105.

[3] Goetzberger, Adolf, Joachim Knobloch, and Bernhard Voss. "Crystalline silicon solar cells." New York (1998): 114-118.
[4] Ding, Shuyu. Nanotechnology for single crystalline silicon solar cell applications. Diss. Carleton University, 2015.

[5] Ranjan, Sudhir, Christopher G. Edwards, and B. Erik Ydstie. "Surface texturization of silicon wafers: A comparative experimental investigation for bulk, industrial application." 2013 IEEE 39th Photovoltaic Specialists Conference (PVSC). IEEE, 2013.

[6] Glunz, Stefan W., and Frank Feldmann. "SiO2 surface passivation layers-a key technology for silicon solar cells." Solar Energy Materials and Solar Cells 185 (2018): 260-269.

[7] Standridge, Stacey D., George C. Schatz, and Joseph T. Hupp. "Toward plasmonic solar cells: protection of silver nanoparticles via atomic layer deposition of TiO2." Langmuir 25.5 (2009): 25962600.

[8] Paetzold, Ulrich W., et al. "Simulation-based analysis of plasmonic light trapping in thin-film silicon solar cells." 2013 13th International Conference on Numerical Simulation of Optoelectronic Devices (NUSOD). IEEE, 2013.

[9] Maier, Stefan Alexander. Plasmonics: fundamentals and applications. Springer Science \& Business Media, 2007. 
[10] Kawata, Satoshi, and Hiroshi Masuhara. Nanoplasmonics: From Fundamentals to Applications: Proceedings of the 2nd International Nanophotonics Symposium Handai, July 26-28th 2004, Suita Campus of Osaka University, Osaka, Japan. Elsevier Science Ltd, 2006.

[11] Zhang, Yinan. Plasmonic enhanced light absorption for silicon wafer-based solar cells. Diss. Swinburne University of Technology Melbourne, Australia 2014, 2014.

[12] Atwater, Harry A., and Albert Polman. "Plasmonics for improved photovoltaic devices." Materials For Sustainable Energy: A Collection of Peer-Reviewed Research and Review Articles from Nature Publishing Group. 2011. 1-11.
[13] Catchpole, KR and, and Albert Polman. "Plasmonic solar cells." Optics express 16.26 (2008): 21793-21800.

[14] Bingham, Julia Marie. Fundamental and applied localized surface plasmon resonance spectroscopy studies from nanoparticle arrays to single nanoparticles. Diss. Northwestern University, 2010.

[15] Homola, Jiř́, Sinclair S. Yee, and Günter Gauglitz. "Surface plasmon resonance sensors." Sensors and Actuators B: Chemical 54.1-2 (1999): 3-15.

[16] Farhadnia, Farshad, Ali Rostami, and Samieh Matloub. "Impacts of Nanoparticles and Nano Rod Arrays on Optical Generation Rate in Plasmonic-Based Solar Cells." (2017): 103-112.

[17] www.comsol.com. 